\title{
Wpływ kąta wierzchołkowego elektrody wolframowej na kształt strefy obrobionej w metodzie TIG
}

\author{
The influence of apex angle \\ on the treated area using TIG method
}

\section{Streszczenie}

Niniejszy artykuł dotyczy wpływu kąta wierzchołkowego na wielkość strefy obrobionej przy użyciu metody TIG. W ramach pracy wykonano próby modyfikacji warstwy wierzchniej dwóch materiałów: żelaza ARMCO i stali C45. Obróbkę wykonano przy dwóch natężeniach prądu, stałej prędkości, i kącie wierzchołkowym w zakresie od $20^{\circ}$ do $60^{\circ}$, stosując dwa gazy osłonowe: argon i hel. Jakość obróbki oceniano na podstawie badań wizualnych, badań mikroskopowych i pomiarów mikrotwardości strefy obrobionej.

Słowa kluczowe: metoda TIG, obróbka cieplna, żelazo ARMCO

\section{Abstract}

The paper presents results of the influence of apex angle on the treated area using TIG method. As part of the work has been done trying to modify the surface treatment of two materials: ARMCO iron and C45 steel. The treatment was performed at two currents, constant speed and an apex angle in the range of $20^{\circ}$ to $60^{\circ}$ using argon and helium as the shielding gases. The quality of obtained treated surfaces were assessed on the basis of visual inspection, macrostructure examination and measurement of microhardness.

Keywords: TIG method, thermal treatment, iron ARMCO

\section{Wstęp}

Powszechnie znana metoda TIG (ang. tungsten inert gas), oznaczona jest także kodem 141. Łuk w tej metodzie jarzy się pomiędzy elektrodą nietopliwą - wolframową (zielona) lub wolframu $z$ dodatkami (tor, lantan, cer - inne kolory oznaczeń) a spawanym materiałem, cały proces prowadzony jest w atmosferze gazu obojętnego, najczęściej argonu bądź helu.

„Jest to najczystszy z wszystkich procesów spawania łukowego, porównywany z metalurgicznego punktu widzenia, do mikroodlewania precyzyjnego w osłonach gazowych" [1].

$\mathrm{Na}$ efekt procesu spawania bezpośredni wpływ mają parametry prądowo napięciowe procesu, rodzaj i wydatek gazu osłonowego, rodzaj materiału elektrody i wielokrotnie pomijany kąt wierzchołkowy elektrody.

W niniejszym artykule przedstawiono wybrane wyniki badań na temat wpływu zmieniającego się kąta wierzchołkowego elektrody wolframowej w metodzie TIG na kształt stre- fy obrobionej. Badania wykonano dla kątów od $20^{\circ}$ do $60^{\circ}$, dla dwóch materiałów na bazie żelaza i dla dwóch rodzajów gazów osłonowych. Weryfikacji efektów obróbki dokonano na podstawie badań wizualnych i metalograficznych charakterystycznych obszarów oraz wyznaczono rozkłady twardości.

\section{Przygotowanie próbek do badań}

Do badań wykorzystano dwa materiały na bazie żelaza: żelazo ARMCO i stal C45 o składzie chemicznym przedstawionym w tablicy I.

Z powyższych materiałów przygotowano w sposób mechaniczny próbki o wymiarach $20 \times 20 \times 5 \mathrm{~mm}$, zaś powierzchnię poddawaną obróbce przeszlifowano papierem ściernym 200 w celu usunięcia warstwy tlenków.

Do prób przetapiania użyto elektrod o $\emptyset 2,4$ mm wykona-

Tablica I. Skład chemiczny żelaza ARMCO i stali C45 [2,3]

Table I. Chemical composition of iron ARMCO and C45 steel

\begin{tabular}{|l|c|c|c|c|c|c|c|c|c|c|c|}
\hline \multirow{2}{*}{ Materiał } & \multicolumn{10}{|c|}{ Zawartość pierwiastków [\%] } \\
\cline { 2 - 11 } & $\mathrm{C}$ & $\mathrm{Mn}$ & $\mathrm{Si}$ & $\mathrm{P}$ & $\mathrm{S}$ & $\mathrm{Cr}$ & $\mathrm{Ni}$ & $\mathrm{Cu}$ & $\mathrm{Mo}$ & $\mathrm{N}$ & $\mathrm{Sn}$ \\
\hline ARMCO & $\leq 0,02$ & $\leq 0,1$ & - & $\leq 0,01$ & $\leq 0,02$ & $\leq 0,03$ & $\leq 0,03$ & $\leq 0,02$ & $\leq 0,02$ & $\leq 0,005$ & $\leq 0,01$ \\
C45 & 0,46 & 0,65 & $\leq 0,40$ & $\leq 0,045$ & $\leq 0,045$ & $\leq 0,3$ & $\leq 0,3$ & $\leq 0,3$ & $\leq 0,1$ & - & - \\
\hline
\end{tabular}

Inż. Bartosz Kaczorowski; dr inż. Paweł Kołodziejczak - Politechnika Warszawska.

Autor korespondencyjny/Corresponding author. pkolodzi@wip.edu.pl 
nych z wolframu z dodatkiem lantanu $(98,5 \%$ wolframu i $1,5 \%$ tlenku lantanu), zaostrzonych precyzyjnie na kąty $20^{\circ}, 30^{\circ}$, $40^{\circ}, 50^{\circ}, 60^{\circ}$.

W celu zapewnienia precyzyjnego ruchu obrabianej powierzchni względem palnika zastosowano stół sterowany numerycznie z zamontowanym imadłem (rys. 1.)

Dla każdego z materiałów wykonano próby dla dwóch natężeń prądu 90 i 120A, stałej prędkości 500 mm/min i przy stałej odległości elektrody od obrabianej powierzchni $2 \mathrm{~mm}$, próby powtórzono dla argonu i helu.

\section{Badania wizualne}

$\mathrm{Na}$ każdej próbce wykonano dwie próby przetopienia dla tego samego natężenia prądu i tego samego kata wierzchołkowego elektrody, jedna wykonana w osłonie argonu (górne przetopienie), a druga w helu (dolne przetopienie), tablica II.

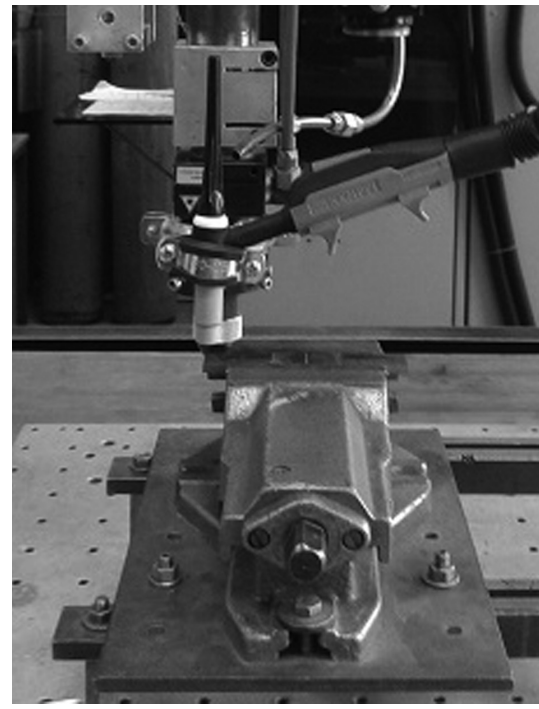

Rys. 1. Stół do obróbki próbek

Fig. 1. Treatment of the sample table

Tablica II. Widok powierzchni po wykonanej obróbce

Table II. The surfaces after thermal treatment

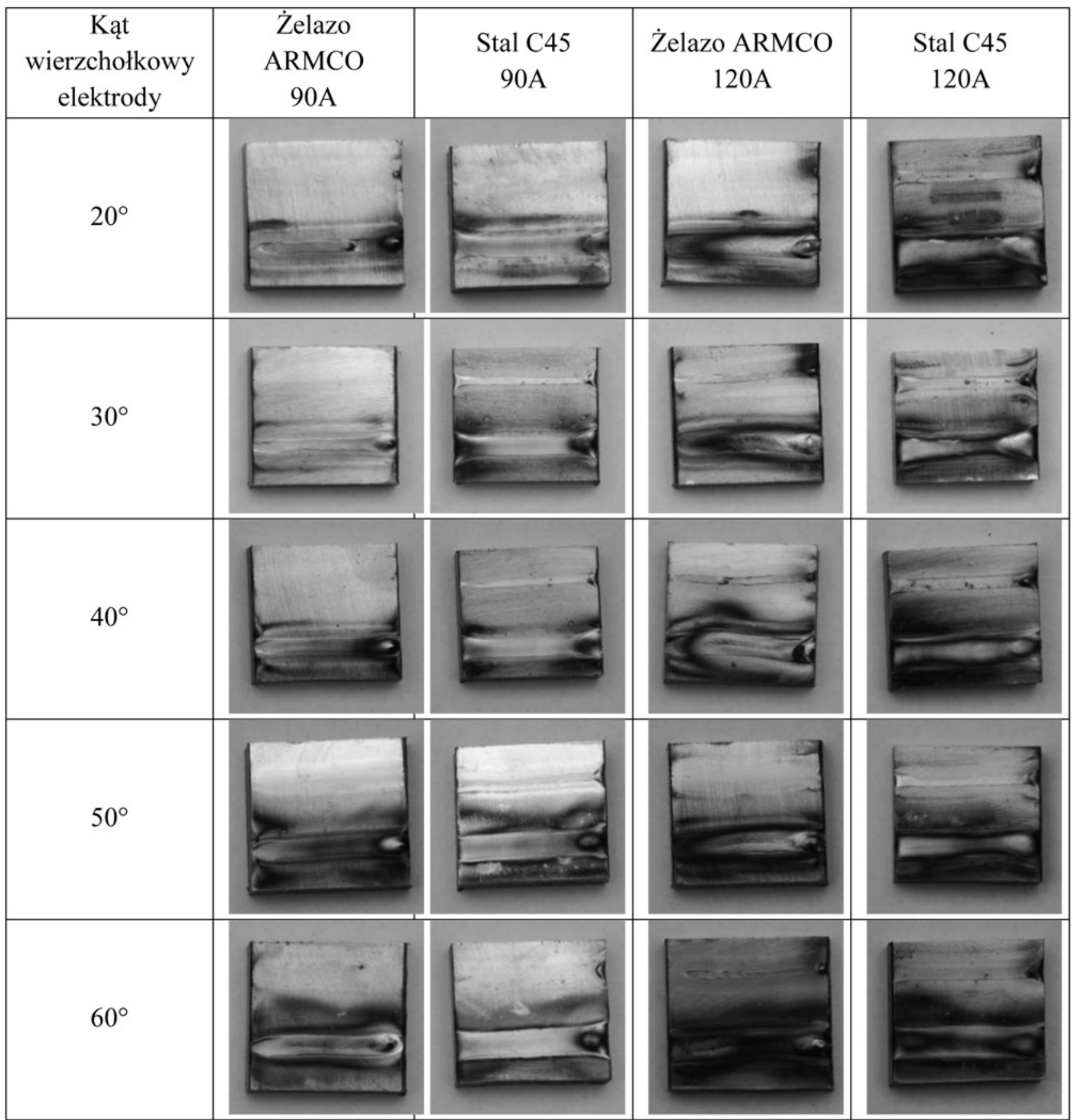


Ze względu na wyższy potencjał jonizacji helu w stosunku do argonu, a tym samym mniejszą skłonność do tworzenia plazmy, próbki wykonane w osłonie helu charakteryzują się większą szerokością strefy przetopionej. Pojawienie się na powierzchni większej ilości tlenków świadczy także o wyższej temperaturze powierzchni w czasie obróbki [4].

Na podstawie badań wizualnych (tabl. II.) można zauważyć, że niezależnie od zastosowanego gazu osłonowego i kąta wierzchołkowego, wraz ze wzrostem natężenia prądu rośnie szerokość przetopienia, która zależy także od materiału zastosowanego do wykonania prób.

Dla próbek z żelaza ARMCO, wykonanych w osłonie helu przy natężeniu prądu $120 \mathrm{~A}$, oprócz kąta $20^{\circ}$ można zauważyć, że doszło do zjawiska tzw. „błądzenia” łuku elektrycznego. Jest to związane $z$ właściwościami ferromagnetycznymi żelaza ARMCO.

Przyjmując jako nadrzędne kryterium szerokość przetopienia można stwierdzić, że dużo lepsze efekty uzyskano przy zastosowaniu helu, natomiast kąty ukosowania elektrod można ustawić w następującej kolejności: $30^{\circ} \rightarrow 40^{\circ} \rightarrow$ $\rightarrow 50^{\circ} \rightarrow 60^{\circ} \rightarrow 20^{\circ}$.

\section{Badania metalograficzne}

W celu przygotowania próbek do badań mikroskopowych otrzymane próbki przecięto mechanicznie prostopadle do kierunku przetapiania w odległości około $5 \mathrm{~mm}$ od krawędzi, wyszlifowano i wypolerowano. Tak wykonane powierzchnie trawiono nitalem przez ok. 30s. Uzyskane zgłady metalograficzne poddano obserwacjom na mikroskopie optycznym OLYMPUS XI70 z cyfrową rejestracją obrazu. Przy użyciu specjalistycznego oprogramowania graficznego wykonano pomiary podstawowych parametrów geometrycznych obszaru przetopienia, dla wszystkich próbek.

Na rysunkach $2 \div 5$ przedstawiono przykładowe przekroje próbek z żelaza ARMCO i stali C45, wykonanych przy natężeniu prądu 120A, kącie wierzchołkowym elektrody $30^{\circ}$ w osłonie argonu i helu.

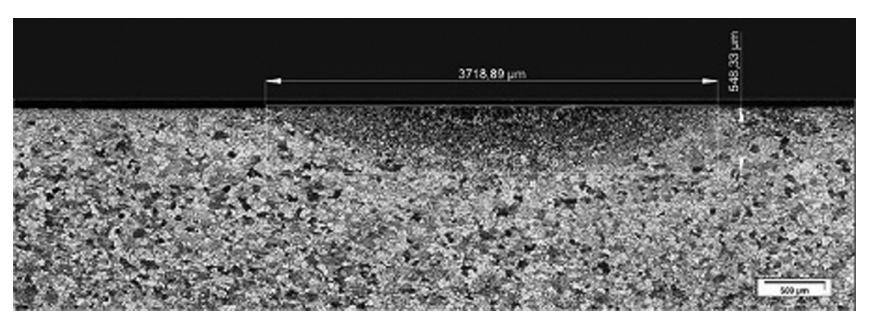

Rys. 2. Materiał: żelazo ARMCO, gaz osłonowy: argon

Fig. 2. Material: iron ARMCO, shielding gas: argon

Analizując $w$ trakcie badań wizualnych próbkę zamieszczoną na rysunku 2 zauważono brak przetopienia, co potwierdziły badania metalograficzne. W wyniku oddziaływania łuku elektrycznego z powierzchnią żelaza ARMCO w osłonie, nastąpiło tylko nagrzanie powierzchni do temperatury powodującej zmiany strukturalne w obszarze obróbki $\left(1,43 \mathrm{~mm}^{2}\right)$ bez jego przetapiania, który można nazwać strefą wpływu ciepła - SWC. Zmieniając gaz osłonowy na hel (rys. 3.) uzyskano przetopienie obrabianej powierzchni. $\mathrm{Na}$ obrazie mikroskopowym można wyodrębnić dwa obszary: obszar przetopiony i SWC, sumaryczna powierzchnia strefy o zmienionej strukturze w wyniku obróbki jest trzykrotnie większa niż w przypadku argonu, i wynosi 4,35 mm².

Analizując otrzymane rezultaty obróbki próbek ze stali C45 (rys. 4 i 5) wykonanych przy takich samych parametrach jak dla próbek przedstawionych na rysunkach 2 i 3, że niezależnie od zastosowanego gazu osłonowego można wyodrębnić dwa obszary: przetopiony i SWC.

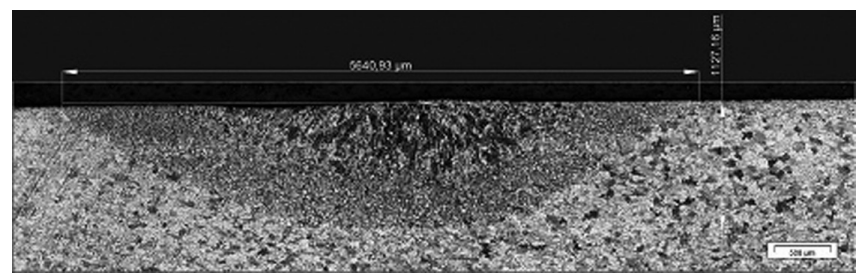

Rys. 3. Materiał: żelazo ARMCO, gaz osłonowy: hel

Fig. 3. Material: iron ARMCO, shielding gas: helium

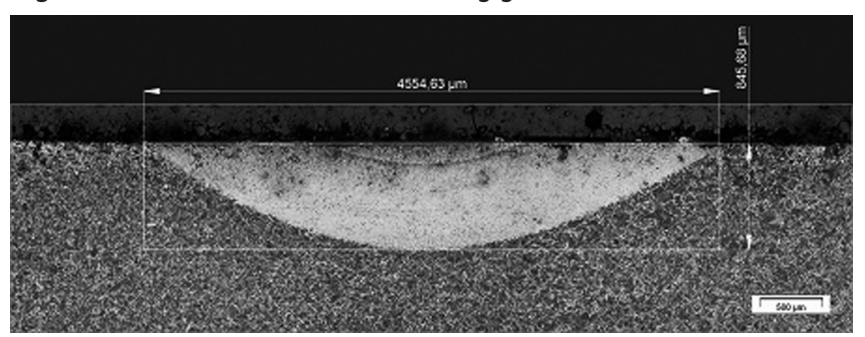

Rys. 4. Materiał: stal C45, gaz osłonowy: argon

Fig. 4. Material: C45 steel, shielding gas: argon

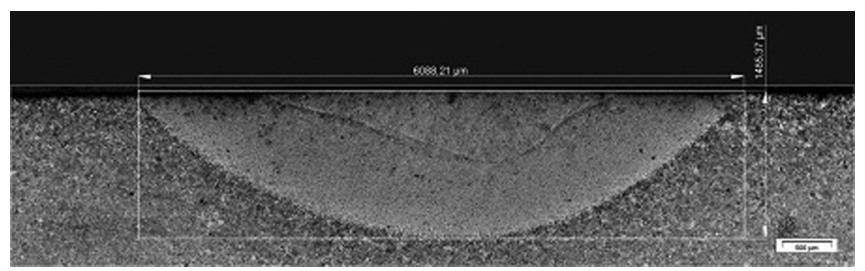

Rys. 5. Materiał: stal C45, gaz osłonowy: hel

Fig. 5. Material: C45 steel, shielding gas: helium

Zmiana gazu osłonowego na hel (rys. 5.) w stosunku do próby wykonanej w argonie (rys. 4.) spowodowało powiększenie obszaru obrobionego o ok. 30\% z większym udziałem strefy przetopionej. Analizując głębokość obszaru o zmienionej strukturze zaobserwowano niespełna dwukrotny jej wzrost.

Zestawienie wymiarów geometrycznych obszarów obrobionych cieplnie dla pozostałych próbek zamieszczonych

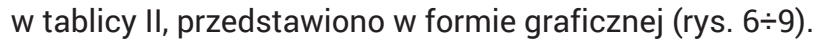

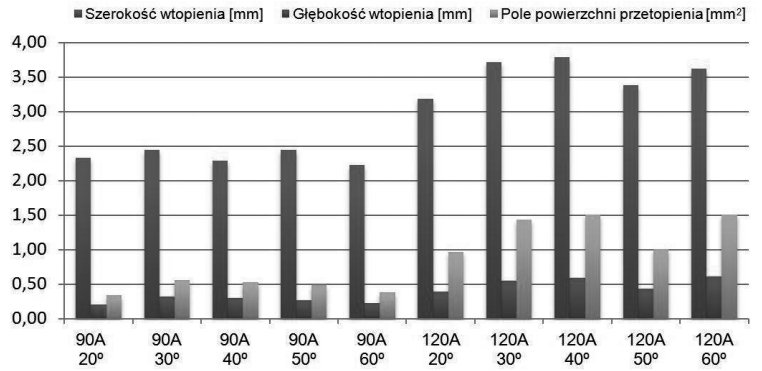

Rys. 6. Parametry geometryczne obszaru obrobionego cieplnie żelaza ARMCO w osłonie argonu

Fig. 6. Geometric parameters of thermal treated area of iron ARMCO with argon as a shielding gas

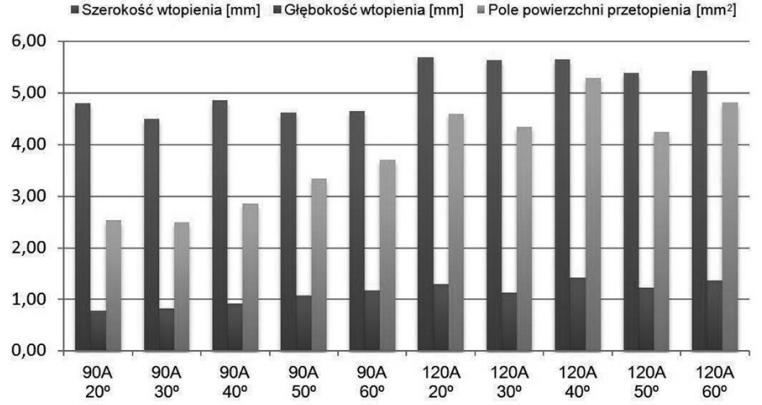

Rys. 7. Parametry geometryczne obszaru obrobionego cieplnie żelaza ARMCO w osłonie helu

Fig. 7. Geometric parameters of thermal treated area of iron ARMCO with helium as a shielding gas 
- Szerokość wopienia [mm] \#Glębokość wtopienia [mm] =Pole powierzchni przetopienia [mm²]

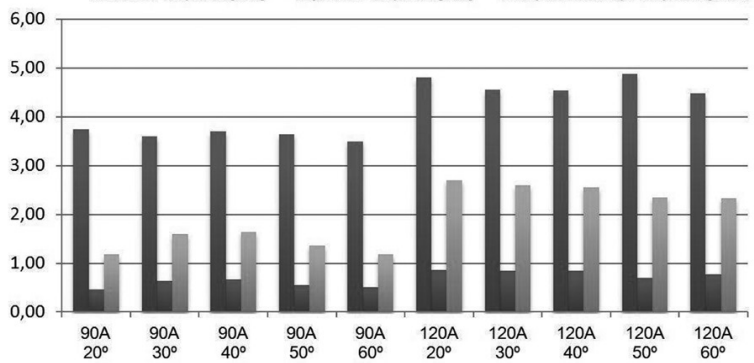

Rys. 8. Parametry geometryczne obszaru obrobionego cieplnie stali C45w osłonie argonu

Fig. 8. Geometric parameters of thermal treated area of C45 steel with argon as a shielding gas

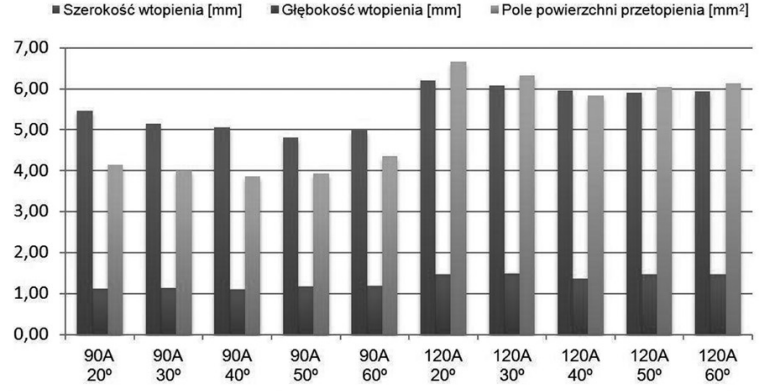

Rys. 9. Parametry geometryczne obszaru obrobionego cieplnie stali C45 w ostonie helu

Fig. 9. Geometric parameters of thermal treated area of C45 steel with helium as a shielding gas

Analiza parametrów geometrycznych obszarów obrobionych potwierdziły informacje zawarte $w$ literaturze, dotyczące ich wzrostu wraz ze zwiększaniem natężenia prądu spawania [5]. W przypadku żelaza ARMCO obrabianego w argonie zaobserwowano znaczny wzrost głębokości obróbki spowodowany wzrostem natężenia prądu, natomiast przy zastosowaniu helu równice te znacząco się zmniejszyły. Podobne zależności występują także dla stali C45.

\section{Badania twardości}

Pomiary twardości wykonano metodą Vickersa wzdłuż linii pomiarowej równoległej do powierzchni obrabianej w od- ległości około 0,2 mm, stosując obciążenie wgłębnika $100 \mathrm{~g}$ dla żelaza ARMCO i $200 \mathrm{~g}$ dla stali C45. Badania wykonano w temperaturze pokojowej na powierzchni przekroju prostopadłego do kierunku spawania po uprzednim jej wypolerowaniu. Na rysunkach 10 i 11 przedstawiono przykładowe rozkłady twardości dla żelaza ARMCO i stali C45.

Analiza rozkładów twardości potwierdziła zdolność stali C45 do hartowania, dla której zanotowano wzrost twardości do ponad $700 \mathrm{HV} 0,2 \mathrm{w}$ obszarze obrobionym w stosunku do materiału rodzimego - 200HV0,2. Nie zanotowano jednak wpływu kąta wierzchołkowego elektrody i rodzaju gazu osłonowego na wzrost twardości na skutek przeprowadzonej obróbki.

W próbkach z żelaza ARMCO, mimo braku węgla w składzie chemicznym zanotowano wzrost twardości w obszarze obrobionym w stosunku materiału rodzimego o ok. 50 jednostek HV0,1, spowodowane jest, to zmianami strukturalnymi spowodowanymi oddziaływaniem łuku elektrycznego.

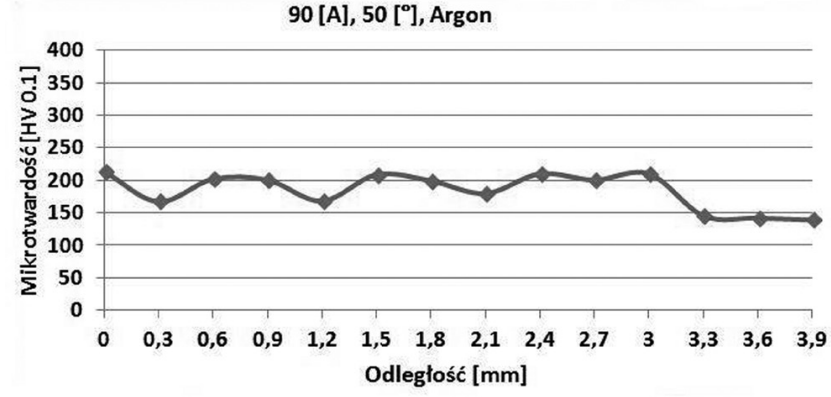

Rys. 10. Rozkład mikrotwardości dla żelaza ARMCO

Fig. 10. The microhardness distribution for iron ARMCO

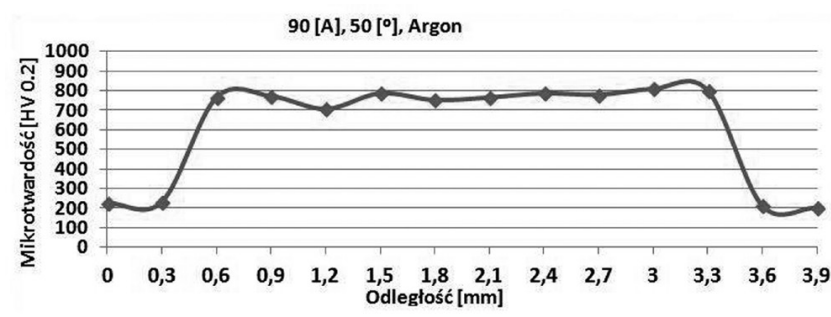

Rys. 11. Rozkład mikrotwardości dla stali C45

Fig. 11. The microhardness distribution for $\mathrm{C} 45$ steel

\section{Podsumowanie}

Na podstawie przeprowadzonych badań można stwierdzić, że wraz ze wzrostem natężenia prądu spawania, niezależnie od gazu osłonowego wzrasta szerokość obszaru obrobionego.

Zmiana gazu osłonowego z argonu na hel skutkuje w głównej mierze zmianą głębokości obszaru obrobionego.

Mimo tych samych warunków obróbki zaobserwowano różne wymiary geometryczne obszaru obrobionego dla żelaza ARMCO i stali C45, obserwując jednocześnie zjawisko „błądzenia łuku” dla żelaza ARMCO występujące głównie dla natężenia prądu 120A.

Zaobserwowano znaczący wzrost twardości w obszarze obrobionym stali C45, co świadczy o jej zahartowaniu.

\section{Literatura}

[1] A. Klimpel: Podręcznik spawalnictwa T. 1, Technologie spawania i cięcia, Wydawnictwo Politechniki Śląskiej, Gliwice 2013

[2] http://www.mpcmetal.pl/wyroby-stalowe

[3] http://www.jacek-boron.de/armco.html
[4] K. Ferenc, J. Ferenc: Spawalnicze gazy osłonowe i palne, Wydawnictwo Naukowo-Techniczne, Warszawa 2005

[5] J. Pilarczyk, P. Adamiec: Poradnik inżyniera: Spawalnictwo 1, Wydawnictwo Naukowo-Techniczne 2008 